\title{
EDITORIAL
}

\section{Rescue! Therapy and the paradox of the Barcalounger}

\author{
S.I. Rennard, P. Calverley
}

A ship sinks at sea. The occupants are left floating in the ocean aided only by their life preservers and buoyant pieces of debris. Fortunately, a Coast-Guard cutter, attracted by an SOS sent from the sinking ship, arrives and saves the day. This is a rescue.

Asthma is characterised by episodes of acutely worsening airflow, secondary to bronchospasm. An asthmatic, when exposed to a trigger, may develop acute bronchospasm, together with frightening and sometimes life-threatening symptoms. Rapid-acting bronchodilators, administered in a timely way, can reverse the bronchospasm, thus saving the day. This is termed "rescue" in asthma therapy.

Acute episodes of asthma can be initiated by a variety of triggers ranging from cold air, cigarette smoke, dust, perfume and viral infections, to a variety of allergens including animal dander, insect and mite proteins, plant pollens and mould spores. An asthma attack can vary in severity, rate of onset and rate of resolution. Unexpected symptoms may be less dramatic and relatively mild and may commonly occur in some asthmatics. Unscheduled use of rapid-acting bronchodilators taken for acute symptom relief for all these various episodes is termed "rescue".

This use of rescue treatment has several utilities. Reserving the term rescue for severe "attacks" would require a definition of attacks, a daunting prospect. The concept also has mechanistic validity. The airway in the asthmatic with baseline conditions has its "normal" luminal diameter and airway tone. In response to a stimulus, airway tone acutely increases while airflow acutely decreases. Therefore, when the asthmatic experiences acute symptoms, an acute alteration in the airway diameter is present that can be acutely remedied.

Moreover, the use of rescue medication has proved an important and robust parameter, both for assessing the efficacy of therapeutic agents designed to prevent worsening symptoms and in assessing overall asthma control. As a result, the availability and use of rescue medicines constitutes an important goal in current asthma treatment and patient education. Consistent with this, the proper use of rescue medicines is highlighted in current asthma guidelines [1]. Rescue medication use, therefore, is a routine parameter assessed in clinical trials.

Chronic obstructive pulmonary disease (COPD) is currently the fourth leading cause of death in the USA, and will be the third leading cause of death worldwide by the year 2020 [2]. The most common cause of COPD is cigarette smoking, but as many as $20 \%$ of patients are lifelong nonsmokers [3]. COPD is characterised by the progressive development of airflow limitation that may lead to respiratory failure and death [4]. Superimposed upon this are episodes of

University of Nebraska Medical Center, Omaha, NE, USA

Correspondence: S.I. Rennard, University of Nebraska Medical Center, 985125 Nebraska Medical Center, Omaha, Nebraska 68198-5125, USA. Fax: 1 4025594878. E-mail: srennard@unmc.edu acutely worsening symptoms that often provoke a physician intervention, and these are usually termed exacerbations [5]. In addition to exacerbations, which have proved difficult to define, COPD patients will often experience brief intermittent episodes of acute dyspnoea. These episodes occur more frequently as the disease progresses and are usually treated with rapid-acting bronchodilators, often referred to as rescue medication. This usage represents an extension of the ideas developed in asthma to COPD. While seemingly innocent enough, this common terminology has at least two major problems. First, it ignores the current understanding of the physiological abnormalities present in COPD patients. Secondly, and perhaps more importantly, the concept of rescue can lead to inappropriate therapeutic paradigms.

In contrast to the asthma patient whose airway calibre may be normal at baseline and whose symptoms are due to superimposed acute episodes of bronchospasm, the patient with COPD develops a relatively fixed limitation of expiratory airflow. The severity of this limitation increases progressively over time. As airflow worsens, the ability of individual patients to sustain ventilation required for increased levels of activity diminishes [6]. The majority of patients with COPD respond to this worsening physiological compromise by decreasing their level of activity. As long as breathing requirements remain sufficiently low, symptoms can be minimal. However, should a patient have the sudden need to increase ventilation, for example during exertion, anxiety or intercurrent illness, the patient will experience dyspnoea. As a result, the most common reason patients with COPD experience the acute onset of episodic dyspnoea is not because of any acute worsening in their lungs, but because they have attempted to exert themselves. Rapid-acting bronchodilators can reduce physiological airway tone and may help relieve symptoms in the COPD patient who has developed dyspnoea, for example, when walking upstairs [7, 8]. Symptoms, of course, will also resolve as the patients rests and respiratory demand decreases.

Whether the use of additional medication in such a setting should be termed rescue is more than a philosophical or semantic issue. In contrast to the asthma patient where the airways are dramatically altered, the patient with COPD is usually not different from baseline when acute symptoms occur. Use of rescue medication is, of course, appropriate. However, pretreating the patient with bronchodilators to optimise lung function prior to physical exertion would be a more appealing therapeutic approach. Such treatment is most likely best accomplished not with rapid and potentially shortacting bronchodilators used episodically, but rather with sustained long-acting bronchodilators [9, 10].

Supplemental medication is often used as an outcome variable in clinical trials with COPD patients. In contrast to asthma, where a decrease in rescue medication use may represent a decrease in the sensitivity of the airways to triggers, the situation with COPD is different. Improvement in baseline airflow may decrease the need for supplemental 
medication use. However, an increase in patient activity, unquestionably a good thing, could substantially increase the need for supplemental bronchodilator use. This leads to the "Paradox of the Barcalounger".

Patient X was a 68-yr-old male with long-standing COPD. He had an 80-pack-yr smoking history, a forced expiratory volume in one second of $0.45 \mathrm{~L}$, a carbon dioxide tension of $11.97 \mathrm{kPa}$, an oxygen tension of $8.51 \mathrm{kPa}$ on $3 \mathrm{~L}$ of nasal oxygen and an arterial blood $\mathrm{pH}$ 7.37. When asked if he had shortness of breath, his response was "No". When asked if he experienced dyspnoea on climbing stairs, he responded "I don't do that". When asked about dyspnoea when walking on level ground, he replied "I don't do that either". In fact, his activity was strictly limited to sitting in a "Barcalounger", a level of activity he could sustain without experiencing dyspnoea. Aggressive use of bronchodilators was able to modestly improve his physiological functioning and, together with aggressive attempts at rehabilitation, he was able to sustain a mild degree of ambulation. Paradoxically, he experienced more dyspnoea, for example, when attending his granddaughter's ballet recital, than he had prior to his therapeutic intervention. Both his symptoms and his rescue medication usage increased. However, the fact that he was better off after the initiation of aggressive therapy was clear to him, his family and his physicians.

Supplemental medication use is an important clinical parameter. The use of the term rescue when applied to chronic obstructive pulmonary disease patients should, perhaps, be abandoned. As the term is in common use, this may be difficult. Nevertheless, the usage of the term implies that something acutely negative has happened. This is almost certainly not the case in the majority of episodes where the acute event is an attempt by the patient to increase activity, which is a positive thing. In addition, supplemental medication use may actually increase as a compromised patient improves and attempts to do more. Patients with chronic obstructive pulmonary disease, by definition, are always compromised with regards to lung function. Rescue is not needed for these patients so much as optimisation of physiological functioning.

\section{References}

1. Global Initiative for Asthma (GINA). Global Strategy for Asthma Management and Prevention. http://www.ginasthma. com. Date updated: April 2002; Date accessed: 9 December 2002.

2. Pauwels RA, Buist AS, Calverley PM, Jenkins CR, Hurd SS. Global strategy for the diagnosis, management, and prevention of chronic obstructive pulmonary disease. National Heart, Lung, and Blood Institute/World Health Organisation Global Initiative for Chronic Obstructive Lung Disease (GOLD) Workshop summary. Am J Respir Crit Care Med 2001; 163: 1256-1276.

3. Mannino DM, Gagnon RC, Petty TL, Lydick E. Obstructive lung disease and low lung function in adults in the United States: data from the National Health and Nutrition Examination Survey, 1988-1994. Arch Intern Med 2000; 160: $1683-1689$

4. Fletcher C, Peto R, Tinker C, Speizer FE. The natural history of chronic bronchitis and emphysema. New York, Oxford University Press, 1976; pp. 1-272.

5. Rodriguez-Roisin R. Toward a consensus definition for COPD exacerbations. Chest 2000; 117: 398-401.

6. Piquette CA, Rennard SI, Snider GL. Chronic bronchitis and emphysema. In: Murray JF, Nadel JA, eds. Textbook of Respiratory Medicine. vol. 2. Philadelphia, W.B. Saunders, 2000: 1187-1245.

7. Hay JG, Stone P, Carter J, et al. Bronchodilator reversibility, exercise performance and breathlessness in stable chronic obstructive pulmonary disease. Eur Respir J 1992; 5: 659664.

8. Belman MJ, Botnick WC, Shin JW. Inhaled bronchodilators reduce dynamic hyperinflation during exercise in patients with chronic obstructive pulmonary disease. Am J Respir Crit Care Med 1996; 153: 967-975.

9. Casaburi R, Mahler DA, Jones PW, et al. A long-term evaluation of once-daily inhaled tiotropium in chronic obstructive pulmonary disease. Eur Respir J 2002; 19: 217 224

10. Vincken W, van Noord JA, Greefhorst AP, et al. Improved health outcomes in patients with COPD during $1 \mathrm{yr}^{\prime} \mathrm{s}$ treatment with tiotropium. Eur Respir J 2002; 19: 209-216. 